PREPARED FOR THE U.S. DEPARTMENT OF ENERGY, UNDER CONTRACT DE-AC02-76CH03073

PPPL-3497

PPPL-3497

UC-70

Fusion Ignition Research Experiment System Integration

by

T. Brown

October 2000

N/Princeton PLAsma

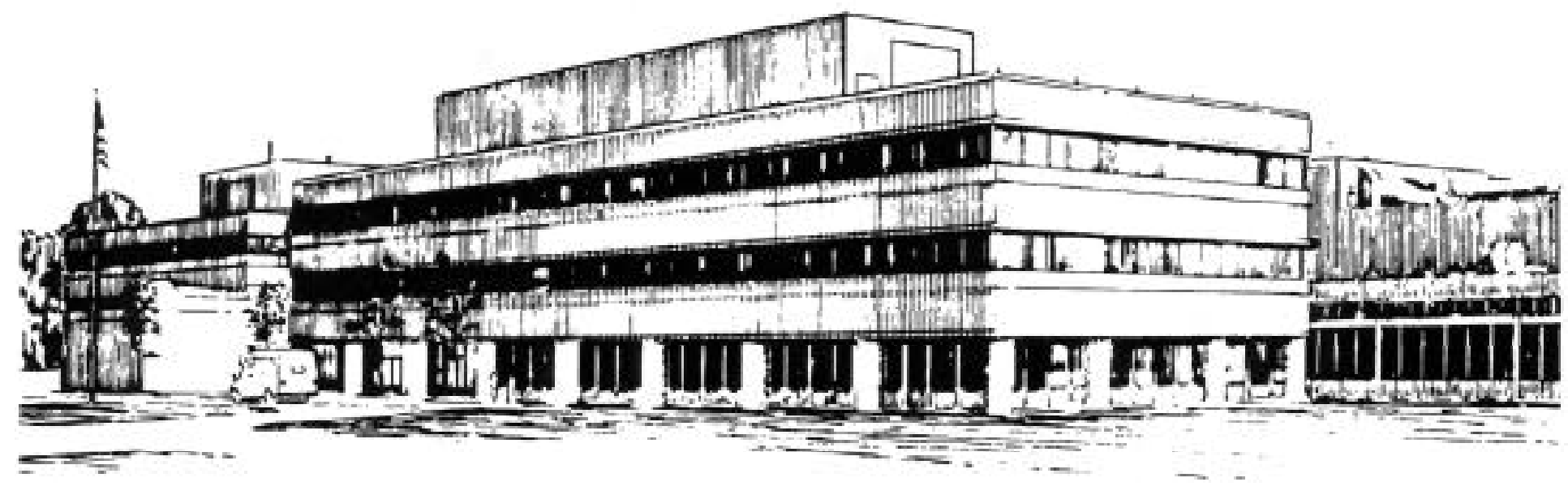

PRINCETON PLASMA PHYSICS LABORATORY PRINCETON UNIVERSITY, PRINCETON, NEW JERSEY 


\section{PPPL Reports Disclaimer}

This report was prepared as an account of work sponsored by an agency of the United States Government. Neither the United States Government nor any agency thereof, nor any of their employees, makes any warranty, express or implied, or assumes any legal liability or responsibility for the accuracy, completeness, or usefulness of any information, apparatus, product, or process disclosed, or represents that its use would not infringe privately owned rights. Reference herein to any specific commercial product, process, or service by trade name, trademark, manufacturer, or otherwise, does not necessarily constitute or imply its endorsement, recommendation, or favoring by the United States Government or any agency thereof. The views and opinions of authors expressed herein do not necessarily state or reflect those of the United States Government or any agency thereof.

\section{Availability}

This report is posted on the U.S. Department of Energy's Princeton Plasma Physics Laboratory Publications and Reports web site in Calendar Year 2000. The home page for PPPL Reports and Publications is: http://www.pppl.gov/pub_report/

DOE and DOE Contractors can obtain copies of this report from:

U.S. Department of Energy

Office of Scientific and Technical Information

DOE Technical Information Services (DTIS)

P.O. Box 62

Oak Ridge, TN 37831

Telephone: (865) 576-8401

Fax: (865) 576-5728

Email: reports@adonis.osti.gov

This report is available to the general public from:

National Technical Information Service

U.S. Department of Commerce

5285 Port Royal Road

Springfield, VA 22161

Telephone: $1-800-553-6847$ or

(703) $605-6000$

Fax: (703) 321-8547

Internet: http://www.ntis.gov/ordering.htm 


\title{
FUSION IGNITION RESEARCH EXPERIMENT SYSTEM INTEGRATION *
}

\author{
T. Brown \\ Princeton Plasma Physics Laboratory \\ P.O. Box 451 \\ Princeton, NJ 08543
}

\begin{abstract}
This paper describes the current status of the FIRE configuration and the integration of the major subsystem components. FIRE has a major radius of $2 \mathrm{~m}$, a field on axis of $10 \mathrm{~T}$, a plasma current of $6.4 \mathrm{MA}$. It is capable of 18 second pulses when operated with DT and $26 \mathrm{~s}$ when operated with DD. The general arrangement consists of sixteen wedged TF coils that surround a free standing central solenoid, a double wall vacuum vessel and internal plasma facing components that are segmented for maintenance through horizontal ports. Large rings located outside the TF coils are used to obtain a load balance between wedging of the intercoil case structure and wedging at the upper/lower inboard corners of the TF coil winding. The magnets are liquid nitrogen cooled and the entire device is surrounded by a thermal enclosure. The double wall vacuum vessel integrates cooling and shielding in a shape that maximizes shielding of ex-vessel components. Within the vacuum vessel, plasma-facing components frame the plasma. First wall tiles are attached directly to inboard and outboard vacuum vessel walls. The divertor is designed for a high triangularity, double-null plasma with a short inner null point-to-wall distance and near vertical outer divertor flux line. The FIRE configuration has been developed to meet the physics objectives and subsystem requirements in an arrangement that allows remote maintenance of in-vessel components and hands-on maintenance of components outside the TF boundary.
\end{abstract}

The design of the baffle and outboard divertor was revised by integrating the two components into a single module. This was done to increase the baffle heat load capacity by provide coolant to the baffle, a component not actively cooled in the earlier design. The reconfigured baffleoutboard divertor module can be extracted through the horizontal ports in a maintenance scheme that provides for component rotation and a vertical lift.

Other changes have been made to the FIRE design. This includes: the elimination of the center tie rod, reworking the vacuum vessel design to allow active cooling of the inboard wall, developing the TF and PF coil structure details, revising the vertical build of the thermal shield and making changes to the FIRE facility layout.

\footnotetext{
* Supported by USDOE Contract Number DE-AC02-76-CH03073
}

\section{Design Configuration and Integration}

The isometric view of Figure 1 shows the FIRE experimental device with the insulation enclosure partially cut back to expose the core components. An in-vessel remote maintenance module is also shown attached to one port. Figure 2 highlights in greater detail the major device core components.

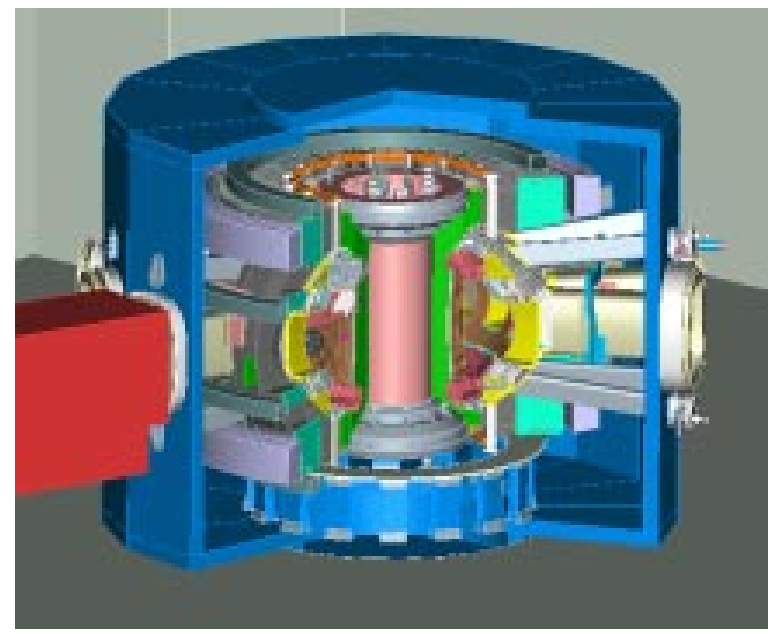

Figure 1. Cross-Sectional View of FIRE Through the Insulation Enclosure

The characteristic features of the FIRE device include:

- Double null, high triangularity gaseous divertors with an outer module that has tungsten plates mounted on actively cooled cooper backing plate.

- A double-walled vacuum vessel with integral shielding.

- Sixteen wedged TF coils that are inertially $\mathrm{LN}_{2}$ cooled, with a partial coil case. High strength $\mathrm{BeCu}$ C17510 is used in the inner legs; OFHC copper is used in the remainder of the coil. 
- Compression rings girdle the TF coils to suppress "de-wedging" in the upper and lower inside corners of the coils.

- An active control coil system consisting of a pair of coils is located within the outboard vessel jacket.

- The entire device is in a thermal enclosure similar to the design used for C-Mod (i.e., polyimide foam insulation with fiberglass inner and outer protective/structural skins).

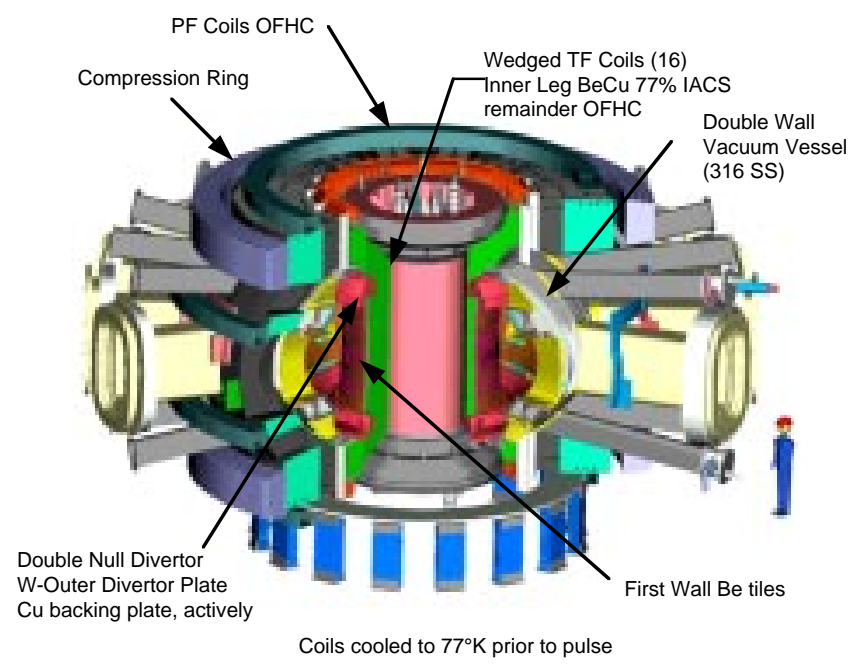

Figure 2. Isometric View Illustrating the Major Core Components

A study was performed to examine the tradeoffs between 12 and 16 toroidal field coils for the FIRE tokamak. The baseline FIRE configuration incorporates a TF geometry that has some of the TF plate windings cut back in the local area of the horizontal ports to provide space for a wider port to improve plasma access (see Figure 3). The tradeoff study was initiated to evaluate the design and cost difference brought about by either increasing the size of the $16 \mathrm{TF}$ coil geometry or reducing the number of coils to improve plasma access, eliminating the need for the local cuts on the winding. The primary advantage of fewer TF coils is that it provides better access for remote maintenance. The primary disadvantage is the higher toroidal field ripple in the plasma. The use of ferromagnetic material for part of the vacuum vessel shielding can reduce the ripple to acceptable values, but can only be optimized for one toroidal field value. In addition, the extra complexity for analysis, plasma startup/control, and diagnostics would be significant. In addition, although fewer, larger ports would make maintenance of the internal components easier and provide a net increase in access area of $20 \%$, it is still possible to maintain the internal components through the smaller ports of $16 \mathrm{TF}$ coil configuration. This study concluded that 16 coil, with local winding cuts, should be retained as the baseline configuration since it meets all requirements with a lower overall cost machine.

In developing the details of the PF solenoid, adding the leads and supporting structure, it was concluded that the marginal benefit of a center tie rod did not warrant the added complexity of its integration with the solenoid service details, so the tie rod was eliminated.

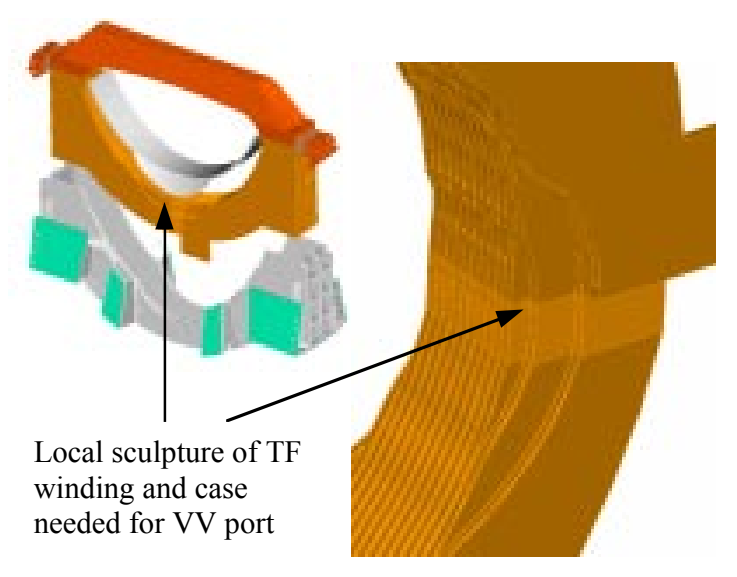

Figure 3. Local TF Winding Cutout

\section{Component Design Updates}

The vacuum vessel was reworked to allow active cooling of the inboard wall. Its double wall geometry forms an inner surface that closely follows the contour of the plasma allowing space for the poloidal limiter, outboard passive plates and the divertor components. The vacuum vessel was split into $45^{\circ}$ octants from the original design of $90^{\circ}$ sectors to reduce the total weight of a $\mathrm{TF} / \mathrm{VV}$ assembly that will be handled during final assembly.

Figure 4 shows a cask with the in-vessel transporter docked to a $45^{\circ}$ vacuum vessel octant and a local blow-up of the divertor module. The boom has a new end-effector design that has been developed specifically for the 800 $\mathrm{kg}$ combined divertor/baffle module. The divertor weight and resulting torque was too great for a harmonic drive type pitch joint so a ball screw drive/four bar linkage scheme was adopted. The detailed interface to the divertor has not yet been developed. The Clearance to the port walls is approximately $20 \mathrm{~mm}$ all around. Deflection of the boom at full extension and load is about $16 \mathrm{~mm}$ assuming $6 \mathrm{~mm}$ boom box sections, which could be increase. The boom can reach far enough to handle half 


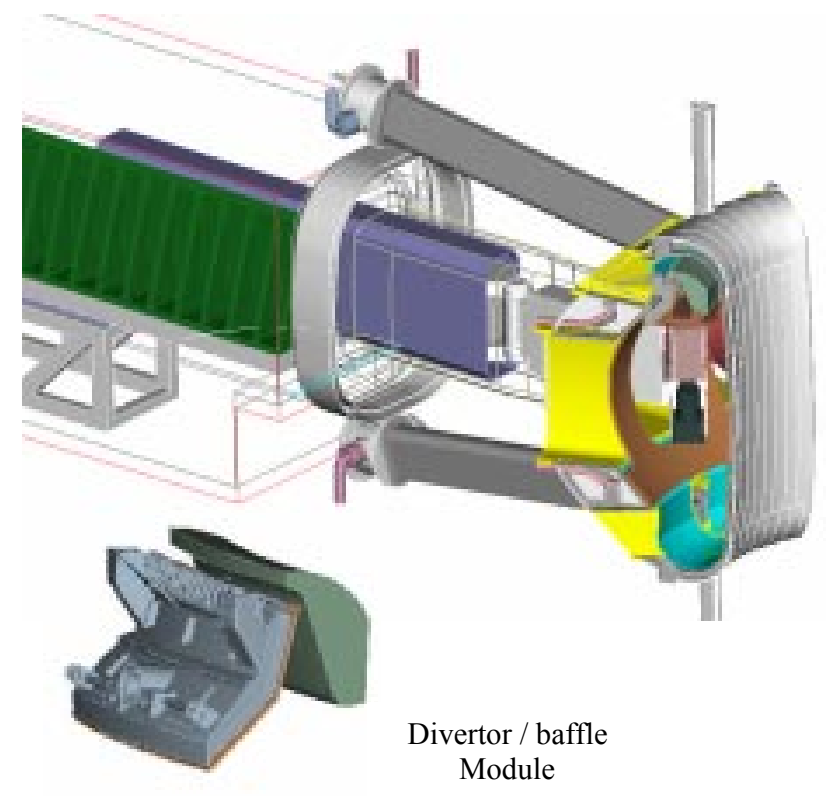

Figure 4. VV / Divertor/RM Details

of the divertors from one port. The cask is 8 meters long, including room to open and close a hinged port-docking door.

The outboard divertor and baffle has been combined into a single module to simplify coolant connections to the baffle. This was required to allow active cooling of the baffle in order to meet a higher heat load requirement. As shown in the local figure the baffle detail is currently shown as an envelope that will be updated in further design developments.

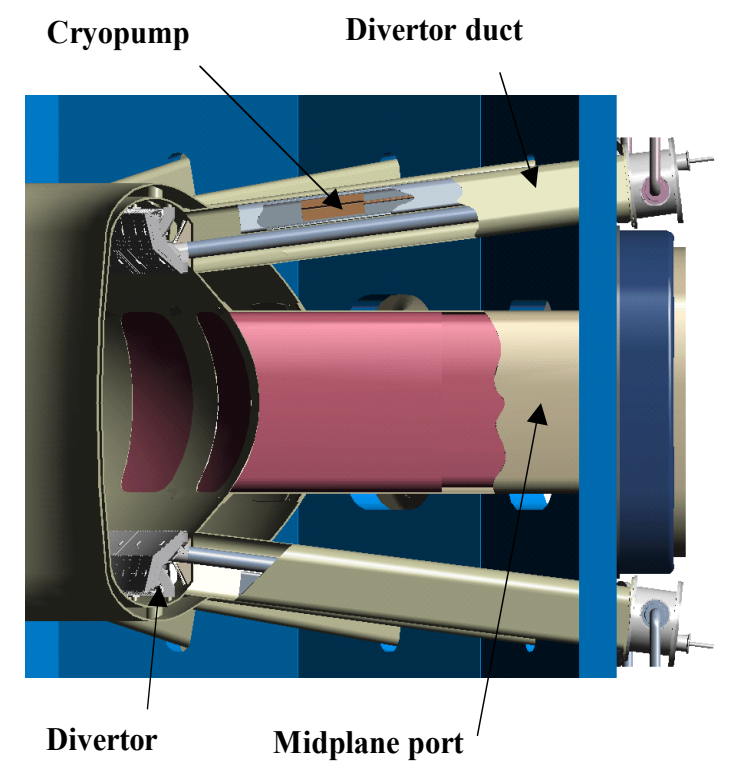

Figure 5. VV Port Details
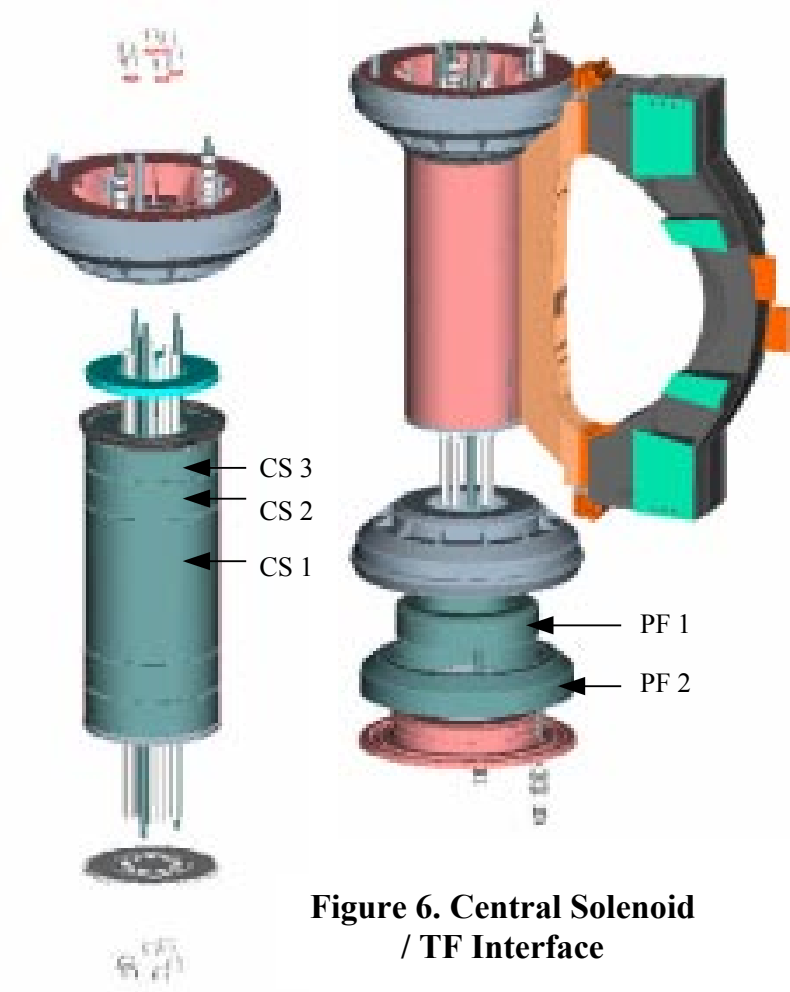

Figure 6. Central Solenoid / TF Interface

The FIRE configuration has sixteen large "straight-in" view ports that are equally distributed along the vacuum vessel mid-plane. Sixteen upper and lower auxiliary ports are provided, angled in a position to allow diagnostic view of the divertor region. Small circular ports are also located at the top and bottom of the vacuum vessel, passing through the region between the TF coil winding.

The horizontal ports provide access to the ancillary systems outside the device. Three ports are assigned to RF heating, and the remaining ports allocated to diagnostics, and in-vessel PFC coolant routings. The angled auxiliary ports, located in the upper and lower vessel regions, accommodate cryopumps, the divertor cooling lines and some diagnostics (see Figure 5).

Support structure and lead details were added to the central solenoid and the space requirements needed for them resulted in the elimination of a large central tie rod system designed in the original baseline configuration. Figure 6 shows the interface between a TF coil, the center solenoid (CS) and divertor shaping coils. A glass epoxy shell with bellows and steel end rings surrounds five CS coils (a center coil and two upper/lower coil sets), forming a containment system for the CS coil $\mathrm{LN}_{2}$ coolant. The divertor shaping coils (PF1 and PF2) are housed in a stainless steel cast structure that provides coil support and manifolding of the nitrogen coolant. A series of tie rods pass through the upper shaping coil support enclosure and extend through the CS assembly to form a CS/upper divertor coil unit that can be assembled as a single module. The length of the tie rod extends far enough to pass 
through and provide attachment for the lower divertor coil assembly, as shown in Figure 6.

The TF coil case structure, updated since the release of the baseline design, makes an extensive use of castings. Figure 7 highlights the detail of the TF case structure in an exploded view showing the case subassemblies and TF winding. Although shown as a vertical view the coil windings would be lowered into the outer case subassembly in the horizontal position and the inner bore case assembly inserted and welded along the edges.

Figure 8 shows a section view of the FIRE device highlighting the major dimensions of the core components.

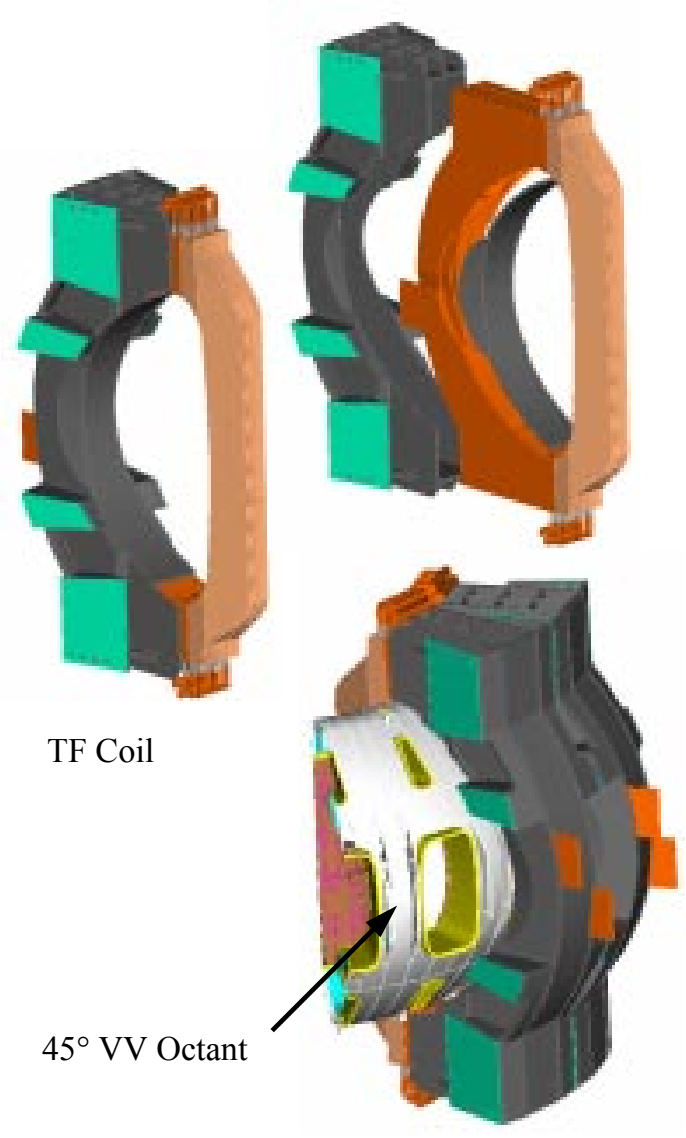

Figure 7. VV / TF Octant Assembly

\section{Machine Assembly}

The FIRE device assembly was altered to use a $45^{\circ}$ octant as the module size rather than the baseline approach where the device was assembled in four 90-degree sections built up from a four-coil TF assembly and a 90degree vacuum vessel quadrant. Figure 7 shows a vacuum vessel octant rotated into the bore of a two-coil TF assembly

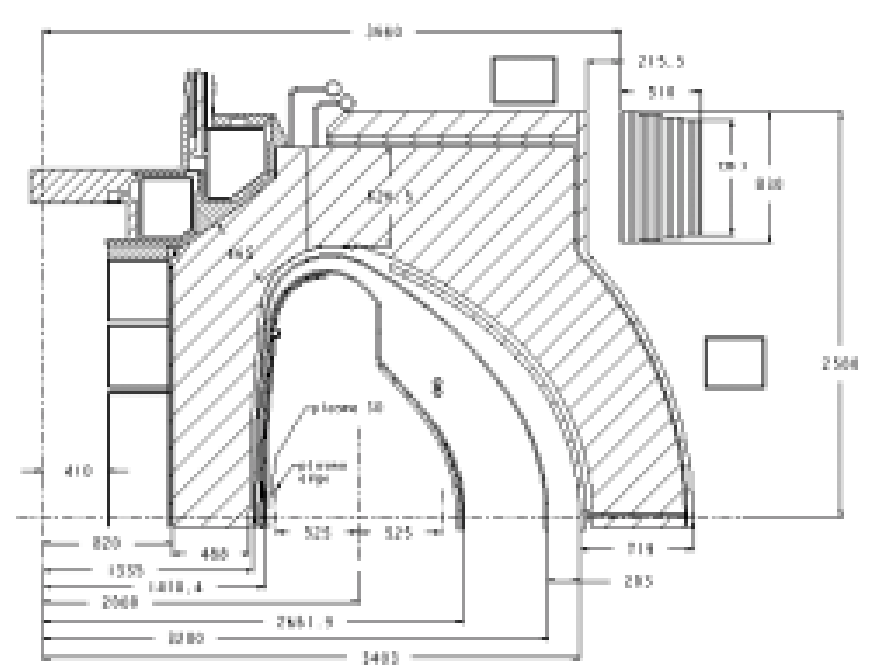

Figure 8. Device Cross Section View

\section{Future Activities}

The FIRE design and integration process will continue to refine the overall device configuration and further develop subsystem details. Preliminary discussions on a possible adjustment of the FIRE design point to attain more physics performance are under way. It is expected that any design variation will involve only minor changes and will not increase the overall cost.

\section{References}

[1] Dale Meade; "Fusion Ignition Research Experiment", Controlled Fusion, Comments on Modern Physics, Vol 2(2), pp. 81-97, 2000

[2] Thome, R. J. et al., "Engineering Features of the Fusion Ignition Research Experiment (FIRE)", $21^{\text {st }}$ Symp. on Fusion Tech., Madrid (2000)

[3] FIRE Design Team; "Fusion Ignition Research Experiment (FIRE) Engineering Status Report for Fiscal Year 2000", Princeton Plasma Physics Laboratory Report No. 81001030_FIREFYRPT_FT.doc 
The Princeton Plasma Physics Laboratory is operated by Princeton University under contract with the U.S. Department of Energy.

\author{
Information Services \\ Princeton Plasma Physics Laboratory \\ P.O. Box 451 \\ Princeton, NJ 08543
}

Phone: 609-243-2750

Fax: 609-243-2751

e-mail: pppl_info@pppl.gov

Internet Address: http://www.pppl.gov 